\title{
Investigaciones en curso
}

La certeza de ser: Acercamiento histórico-sistemático a la encrucijada entre Tomás y Agustin en Edith Stein, "Potenz und Akt». Proyecto Fondecyt Regular 2015-2016 Nro.1150136

El presente Proyecto tiene su encuadre en los Proyectos Fondecyt Regular 1120035 y 1130019 , pero apunta a una novedad radical al pretender descubrir más allá de la relevancia del "sentimiento" y "el espíritu" el significado de la "certeza de ser" en la obra Potenz und Akt de Edith Stein. Esta pensadora potente, que en cuanto discípula de Husserl se sitúa en la encrucijada entre Tomás y Agustín, constituyéndose dicha certeza en la originalidad de su pensamiento. Esto significa que el esfuerzo investigativo del presente Proyecto se centra en la mirada atenta a las fuentes -Tomás y Agustín- a la vez que se proyecta hacia vertientes de la filosofía contemporánea a partir de la fenomenología de Husserl.

La "certeza de ser" es un fenómeno originario, al cual el pensar filosófico-teológico se acerca desde siempre con una actitud crítica, hasta contradictoria, si pensamos en la propuesta de Wittgenstein, criticada por Edmund Runggaldier o de Marion, emplazada por Thomas Alferi a raíz de su interpretación de la II. Meditación de Descartes. Entre tales extremos se gesta, sin embargo, la certeza de ser "simple" a partir de la intelección racional de la Überweltlichkeit husserliana, dilucidada e interrelacionada con la afectividad, por Mariano Crespo. Esta intelección se despliega en Edith Stein a través de una rigurosidad filosófica sorprendente, que se abre hacia el Misterio del ser a partir del espíritu finito anticipado por el Espíritu Infinito en cuanto persona expuesta al no-ser en medio de un mundo agobiado por la falta de certeza y cobijo.

El proyecto pretende verificar esta hipótesis: la certeza de ser, trasciende la razón humana en su índole clara y distinta, aunque se gesta al interior de ella, a la vez que supera al sentimiento, sin tener su anclaje definitivo en él, por ser una novedad que emerge entre ambos, cuando el espíritu finito es anticipado por su fundamento último, el Espíritu Infinito, y se entrega a El, a modo del Espíritu Santo.

El Objetivo General es profundizar la comprensión de la certeza de ser en la obra Potenz und Akt de Edith Stein, a la luz de la influencia de Tomás de Aquino, Agustín 
y Husserl, a fin de capacitar para el uso crítico del método histórico sistemático desde una perspectiva fenomenológica. Esta perspectiva se expresa en el texto, concretando su proyección relevante para el ser humano hoy, situado en un mundo agobiado por la falta de certeza y cobijo por medio de la difusión interdisciplinar.

Las fuentes de la investigación son: EDITH STEIN GESAMTAUSGABE, hrsg Internationales Edith Stein Institut Würzburg Freiburg-Basel-Wien 2004-2008= ESGA; EDITH STEIN, Die ontische Struktur der Person und ihre erkenntnistheoretische Problematik(ESW, VI) Louvain, Freiburg 1962, 185-197; STEIN Edith, Potenz und Akt:Studien zu einer Philosophie des Seins.Eingeführt und bearbeitet von Hans Rainer Sepp, Freiburg 2005 STEIN Edith, Endliches und ewiges Sein. Versuch eines Aufstiegs zum Sinn des Sein. Eingeführt und bearbeitet von Andreas Uwe Müller (ESGA 11/12), Freiburg 2006, 531pp.

La metodología es aquella que ha sido aplicada en los proyectos anteriores, es decir, la interpretación textual mediante un análisis histórico-crítico de los conceptos de mayor alcance filosófico que trasuntan en el significado teológico correspondiente a una investiga- ción histórico-sistemática. Para ser realmente fructífero, este trabajo de exégesis debe combinar adecuadamente tanto los aspectos de rigurosidad histórico-crítica, como los de relevancia sistemática. El primero apunta a evitar extrapolaciones indebidas en el acceso a las fuentes de la historia de la filosofía; el segundo se orienta a rescatar la actualidad de los desarrollos sistemáticos contenidos en dichas fuentes $\mathrm{o}$, al menos, posibilitados por ellas. En este procedimiento se integran los matices propios de cada autor y de su obra seleccionada para una lectura orgánica a partir del texto.

El esfuerzo metódico se lleva a cabo tanto en forma personal como en reuniones periódicas con los coinvestigadores participantes en el proyecto. Reuniones de las cuales se espera, como en los proyectos anteriores, un gran enriquecimiento de perspectivas e impulsos que se abren a la luz del problema abordado. Sin duda, se tendrá especial cuidado de que los aportes de los miembros del equipo no se dispersen, sino que se logre verificar la conexión interna de los argumentos. Se aspira a la elaboración de una publicación adecuada de los resultados, que se redactará en un estudio único, o en artículos diversos de revistas especializadas. Dichos resultados también se traduce en Seminarios de postgrado, Congre- 
sos, Simposios y Coloquios, como en Talleres de Difusión y Diplomados específicos en colaboración con el "Centro de investigación Edith Stein".

6.- Nombres de los investigadores participantes y la responsabilidad que les cabe en la investigación son: Anneliese Meis (Investigadora responsable; Facultad de Teología, Pontificia Universidad Católica de Chile, investiga el problema en la obra steineana); Pamela Chávez (Coinvestigadora; Facultad de Filosofia, Pontificia Universidad Católica de Chile, aborda la certeza en Agustín); y Mariano Crespo (Coinvestigador; Facultad de Filosofía, Universidad de Navarra, España, hace aportes desde sus conocimientos específicos en Edmund Husserl).
Anneliese Meis

Facultad de Teologia

Pontificia Universidad Católica

de Chile 